ORIGINAL ARTICLE

\title{
Status of Serum Copper and Zinc in Pre-Eclampsia
}

\author{
FZ Muna ${ }^{1}$, ASMM Sirazi ${ }^{2}$, M Majumder ${ }^{3}$, \\ K Serajuddin ${ }^{3}$, BC Debnath ${ }^{4}$, MS Hossain ${ }^{3}$ \\ ${ }^{1}$ Dept of Biochemistry, Mugda Medical College, Dhaka \\ ${ }^{2}$ Dept of Medicine, Sylhet MAG Osmani Medical College Hospital, Sylhet \\ ${ }^{3}$ Dept of Biochemistry, Sylhet MAG Osmani Medical College, Sylhet \\ ${ }^{4}$ Department of Biochemistry, Park view Medical College, Sylhet
}

\begin{abstract}
Pre-eclampsia is a multisystem and multifactorial disease that affects both mother and fetus by endothelial dysfunction and intrauterine growth retardation. It is thought that pre-eclampsia is associated with an imbalance of increased lipid peroxides and decreased antioxidants. Dietary deficiency or excess of copper, zinc or other micronutrients play important role in the pathogenesis of pre-eclampsia because nutrients can modulate oxidative stress by increasing or decreasing free radicals or antioxidants and providing substrates for formation of free radicals. This study was carried out in the Department of Biochemistry, Sylhet MAG Osmani Medical College during the period from July 2014 to June 2015 to evaluate the status of serum copper and zinc in pre-eclamptic patients. For this study 85 age-matched women were selected and grouped as 30 pre-eclamptic patients, 27 normal pregnant and 28 nonpregnant women. serum copper and zinc level were measured in all study subjects by AAS. Data were analyzed with the help of SPSS version 17.0. Mean $( \pm$ SD) level of serum copper and zinc were $1.43 \pm 0.49 \mathrm{mg} / \mathrm{l}$ and $2.43 \pm 2.89 \mathrm{mg} / \mathrm{l}$ in pre-eclamptics, while in normal pregnant women the levels were $1.51 \pm 0.47 \mathrm{mg} / \mathrm{l}$ and $2.87 \pm 2.23 \mathrm{mg} / \mathrm{l}$ and in non-pregnant women these were $0.85 \pm 0.28 \mathrm{mg} / 1$ and $3.70 \pm 2.61 \mathrm{mg} / \mathrm{l}$ respectively. Serum copper significantly increased in pre-eclamptics and normal pregnant women when compared with that of non-pregnant women $[F(2,82)=19.763 ; p<0.001]$, but there was no significant difference between pre-eclamptic and normal pregnant group. No significant difference of serum zinc among three groups were observed $[\mathrm{F}(2,82)=1.774 ; \mathrm{p}=0.176]$. The study showed increased trend of serum copper and decreased trend of serum zinc in pregnancy (both preeclampsia and without pre-eclampsia) compared with non-pregnant women, and both were reduced in pre-eclampsia compared to normal pregnancy. As our study did not show any significant difference in copper and zinc level in pre-eclamptics and normal pregnant women hence it can be concluded that there may not be any significant association of serum copper and zinc level with pre-eclampsia.
\end{abstract}

Key Words: Pre-eclampsia, Copper, Zinc

\section{Introduction}

Pre-eclampsia is defined as onset of hypertension to the extent of $140 / 90 \mathrm{~mm}$ of $\mathrm{Hg}$ or more with proteinuria after $20^{\text {th }}$ weeks of pregnancy in a previously normotensive and nonproteinuric woman ${ }^{1}$. Pre-eclampsia is a rapidly progressive systemic disease that affects about $5-7 \%$ of all pregnancies ${ }^{2}$. Incidence of pre-eclampsia in primigravida is about $10 \%$ and in multigravida it is about $5 \%^{3}$. However, the

Bangladesh J Med Biochem 2015; 8(2): 59-54 incidence of pre-eclampsia has fallen in developed countries due to improved antenatal care, but it's incidence is still high in developing countries. Pre-eclampsia and eclampsia are the cause of about $16 \%$ of maternal death in Bangladesh ${ }^{4}$.

Pathophysiology of this multisystem disease is characterized by failure of trophoblastic invasion of the spiral arteries which may be associated 
Stutus of Serum Copper and Zinc in Pre-Eclampsia

with an increased vascular resistance of uterine artery and decreased perfusion of placenta ${ }^{2}$. Uncontrolled lipid peroxidation produces reactive oxygen species in the form of free radicals in pre-eclampsia. Placental oxidative stress showed a key feature in the pathogenesis of pre-eclampsia ${ }^{5}$. It is assumed that dietary deficiency or excess of copper, zinc or other micronutrients play important role in the pathogenesis of pre-eclampsia because nutrients can modulate oxidative stress by increasing or decreasing free radicals as well as antioxidants and providing substrates for formation of free radicals $^{6}$. Pregnant women from developing countries usually consume diets that are low in minerals and vitamins ${ }^{7}$.

Copper is an important constituent of copper dependent enzymes such as lysyl oxidase, cytochrome oxidase, tyrosinase, dopamine hydroxylase, catalase, monoamine oxidase, ALA synthase, ascorbic acid oxidase, phenol oxidase, uricase, superoxide dismutase and thus acts as part of antioxidant defense system ${ }^{8,9}$. During pregnancy lack of these biologically important trace elements impair the antioxidant mechanism leading to increase in oxidative stress ${ }^{10}$.

Zinc is required for DNA replication, transcription and cellular proliferation as it is the metallic component of various enzymes like DNA polymerase, RNA polymerase and thymidine kinase $^{11}$. It is a structural component of several proteins such as growth factors, cytokines, receptors and transcription factors which play an important role in the cellular signaling pathways ${ }^{3}$.

Zinc is also an essential component of several enzymes like carbonic anhydrase, alkaline phosphatase, superoxide dismutase. It may be regarded as an antioxidant since the enzyme superoxide dismutase protects the body against free radical damage. The storage and secretion of insulin from the $\beta$ cell of pancreas require zinc. It promotes the synthesis of retinol binding protein and maintains normal levels of vitamin A in serum. It is required for wound healing, cell growth and division. Gustin, a zinc containing protein of saliva, is important for taste sensation. It is required for proper reproduction ${ }^{9}$.

Some researchers identified that depleted level of copper and zinc acts as a contributing factor to the pathophysiological events of preeclampsia. While others found no such association between pre-eclampsia and trace elements. Inspite of potential possibility of reduced trace elements in pregnancy and variable results of different studies, this study was carried out to evaluate the status of copper and zinc in pre-eclamptic patients, and to search whether reduced copper and zinc are associated with pre-eclampsia or not.

\section{Materials and Methods}

This cross-sectional observational study was carried out in the Department of Biochemistry in collaboration with Department of Obstetrics and Gynecology, Sylhet MAG Osmani Medical College Hospital and Department of Soil, Water and Environment, University of Dhaka during the period from July 2014 to June 2015. For this purpose, 30 primi patients with pre-eclampsia (Group-A), 27 primi with normal pregnancy (Group-B) and 28 non pregnant women (Group-C) were selected. Inclusion criteria were subjects with pre-eclampsia, pregnant women without pre-eclampsia and non-pregnant women. Exclusion criteria were essential hypertension, cardiovascular disease, liver disease, gastro-intestinal disease, renal disease, diabetes mellitus, blood disease, severe anemia.

Informed written consent was taken from each study subject and ethical approval for the study was obtained from the Ethical Committee of Sylhet MAG Osmani Medical College.

Maternal weight, height and blood pressure were recorded. Body mass index (BMI) was calculated. Serum copper and zinc were measured by AAS method.

Data were analyzed with the help of SPSS version 17.0. Anova, Post Hoc (Tukey) and Unpaired " $t$ " test were done to see the level of significance. 


\section{Results}

Mean $( \pm$ SD) age of pre-eclamptic, normal pregnant women and non-pregnant women were $22.73 \pm 2.16$ years, $22.81 \pm 2.17$ years and $23.89 \pm 3.14$ years respectively which showed no significant difference $[\mathrm{F}(2,82)=1.851 ; \mathrm{p}=0.164]$. Gestational age of preeclamptic patients was $33.10 \pm 1.15$ weeks while that of normal pregnant women was $32.63 \pm 1.44$ weeks and the difference was non-significant $(\mathrm{t}=1.364$; $\mathrm{p}=0.178)$ as shown in table-I.

There was significant difference of systolic blood pressure, diastolic blood pressure and mean pressure among pre-eclamptic, normal pregnant and non-pregnant women $(\mathrm{p}<0.001)$ (Table-II).

Serum copper level significantly differed among three groups $[\mathrm{F}(2,82)=19.763 ; \mathrm{p}<0.001]$. The serum copper level was significantly increased in subjects with pre-eclampsia $(\mathrm{p}<0.001)$ and normal pregnant women $(\mathrm{p}<0.001)$ compared to that of non-pregnant women. But there was no significant difference of serum copper level between pre-eclamptics and normal pregnant women $(p=0.747)$. Difference of serum zinc level was not significant among three groups [F $(2,82)=1.774 ; \mathrm{p}=0.176$ ] as shown in table-III.

Table-I: Demographic features of study subjects

\begin{tabular}{cccc}
\hline Demographic features & $\begin{array}{c}\text { Pre-eclampsia } \\
(\mathrm{n}=30)\end{array}$ & $\begin{array}{c}\text { Normal } \\
\text { pregnancy } \\
(\mathrm{n}=27)\end{array}$ & $\begin{array}{c}\text { Non pregnant } \\
(\mathrm{n}=28)\end{array}$ \\
\hline Age (yrs) & $22.73 \pm 2.16$ & $22.81 \pm 2.17$ & $23.89 \pm 3.14$ \\
Gestational age (wks) & $33.10 \pm 1.15$ & $32.63 \pm 1.44$ & na \\
Body mass index (kg/m²) & $24.53 \pm 1.70$ & $23.96 \pm 1.66$ & $23.83 \pm 2.61$
\end{tabular}

Data were analyzed by using ANOVA and unpaired ' $t$ ' test. Age and body mass index were not different among the three groups $(p=0.164$ for age and $\mathrm{p}=0.385$ for $\mathrm{BMI}$ ), and gestational age was similar between pre-eclamptic and normal pregnant women $(\mathrm{p}=0.178)$. na, not applicable.
Table-II: Blood pressure parameters of study subjects

\begin{tabular}{lcrc}
$\begin{array}{c}\text { Blood pressure parame ters } \\
(\mathrm{mm} \text { of Hg) }\end{array}$ & $\begin{array}{c}\text { Pre - eclampsia } \\
(\mathrm{n}=30)\end{array}$ & \multicolumn{1}{c}{$\begin{array}{c}\text { Normal } \\
\text { pregnancy } \\
(\mathrm{n}=27)\end{array}$} & $\begin{array}{c}\text { Non preggant } \\
(\mathrm{n}=28)\end{array}$ \\
\hline Systolic blood pressure & $160.00 \pm 20.34$ & $109.63 \pm 10.55$ & $110.36 \pm 11.05$ \\
Diastolic blood pressure & $104.33 \pm 8.58$ & $68.52 \pm 7.18$ & $67.86 \pm 7.38$ \\
Mean pressure & $122.89 \pm 11.03$ & $81.60 \pm 7.81$ & $82.02 \pm 7.93$ \\
\hline
\end{tabular}

Data were analyzed by using ANOVA and Post Hoc (Tukey) test. Systolic, diastolic and mean blood pressures were significantly different among the three groups $(p<0.001, p<0.001$ and $\mathrm{p}<0.001$, respectively).

Table-III: Serum copper and zinc levels of the study subjects

\begin{tabular}{lclc}
$\begin{array}{c}\text { Biochemical parameters } \\
(\mathrm{mg} / \mathrm{L})\end{array}$ & $\begin{array}{c}\text { Pre eclampsia } \\
(\mathbf{n}=30)\end{array}$ & $\begin{array}{c}\text { Normal } \\
\text { pregnancy } \\
(\mathbf{n}=27)\end{array}$ & $\begin{array}{c}\text { Non pregnant } \\
(\mathbf{n}=28)\end{array}$ \\
\hline Serum copper level & $1.43 \pm 0.49$ & $1.51 \pm 0.47$ & $0.85 \pm 0.28^{*}$ \\
Serum zinc level & $2.43 \pm 2.89$ & $2.87 \pm 2.23$ & $3.70 \pm 2.61$ \\
& & & \\
\hline
\end{tabular}

Data were analyzed by using ANOVA and Post Hoc (Tukey) test. Serum copper levels were significantly different among the three groups $(\mathrm{p}<0.001)$, but serum zinc levels were not significantly different $(p=0.176) .{ }^{*} p<0.001$ pre-eclampsia versus normal pregnancy.

\section{Discussion}

Pre-eclampsia is a multisystem and multifactorial disease that affects both mother and fetus by endothelial dysfunction and intrauterine growth retardation. It is thought that pre-eclampsia is associated with an imbalance of increased lipid peroxides and decreased antioxidants, which ultimately increases the production of ROS. Dietary deficiency or excess of copper, zinc or other micronutrients play important role in pathogenesis of pre-eclampsia. Copper can produce the highly reactive hydroxyl radicals which can begin lipid peroxidation process and cause endothelial cell damage. Zinc counter acts 
oxidation through binding sulphydryl group in proteins and by occupying binding site for iron and copper in lipids, proteins and DNA. Zinc deficiency causes increased lipid peroxidation which also cause endothelial injury and dysfunction.

Due to increased number of pre-eclamptic cases in Bangladeshi women and to evaluate the association of trace elements in pathogenesis of pre-eclampsia, the present study was undertaken to evaluate the pattern of changes of serum copper and zinc in pre-eclamptic patients.

There was no significant difference of age among three groups. This result was similar with other studies $^{3,12,13}$. Our study showed no significant difference between gestational age of preeclamptic and normal pregnant groups which is similar with the study of other researchers ${ }^{3,14,15}$. In this present study BMI of subjects did not differ significantly among the three groups, which is consistent with some studies ${ }^{7,15,16}$.

In our study systolic blood pressure, diastolic blood pressure and mean pressure significantly differed among three groups. The systolic blood pressure, diastolic blood pressure and mean pressure were significantly raised in subjects with pre-eclampsia compared to normal pregnant and non-pregnant women. But no significant difference was observed between normal pregnant and non-pregnant women which is supported by several studies $2,4,7,12,14$.

This study showed increased level of serum copper in pregnancy compared to non- pregnant women which is in agreement with a Turkish study conducted in their population ${ }^{19}$. The physiological importance of these changes remains obscure. But it is presumed that mobilization of copper from maternal tissues (liver) associated with increased estrogen may be responsible for raised copper in pregnancy along with additional damage to organ due to vasoconstriction in toxaemias. Continued rise in estrogen and progesterone during pregnancy may be associated with a rise in ceruloplasmin, to which copper is tightly bound.
Another study showed decreased level of serum copper in normal pregnancy compared to nonpregnant women ${ }^{10}$. The possible reasons of reduced copper may be poor copper diet and decreased absorption of copper in pregnancy. Intestinal irritation during pregnancy causes increased production of gastric acids which lowers the absorption of copper.

In our study, there was no significant difference of serum copper level between pre-eclamptic and normal pregnant women which is partially in agreement with an Indian study ${ }^{17}$. We found decreased level of copper in pre-eclampsia compared to normal pregnancy and but on Indian study found increased level of copper in pre-eclampsia compared to normal pregnancy. A study on Iranian population showed a significantly increased level of serum copper in pre-eclampsia compared to that of normal pregnant women which is in disagreement with our study ${ }^{14}$.

Lower level of serum copper was found in other studies in pre-eclampsia compared to normal pregnant group and the difference was statistically significant which was conducted in Indian, Arabian, Nigerian population ${ }^{2,3,7}$. Some authors also found lower level of serum copper in pre-eclampsia compared to normotensive pregnant women, but the difference was not statistically significant which was conducted in Sudanese population ${ }^{13}$.

In our study serum zinc was reduced in pregnancy (both pre-eclampsia and normal pregnancy) compared to non-pregnant women. There was also a trend of lower serum zinc level in pre-eclampsia compared to normal pregnancy and the difference was not statistically significant which is similar with some studies conducted in Sudanese, Iranian, and Nigerian populations ${ }^{13,14,18}$. Some studies were partially consistent with the present study findings. They showed that the serum zinc level in pre-eclampsia was lower than that in normal pregnant group and the difference was statistically significant in Indian, Arabian and Nigerian populations $\mathbf{s}^{2,3,7}$. 
Zinc deficiency in pre-eclampsia may result from hemodilution due to fluid retention in preeclampsia, endogenous steroid production, fetal uptake of zinc from maternal circulation. Reduced zinc level may also be due to decreased level of zinc binding protein. It is reported that zinc deficiency in pregnancy causes congenital malformation of fetus. Iron, at supplemental dosage (up to $65 \mathrm{mg} /$ day) may decrease zinc absorption, so that pregnant women taking iron may require zinc supplementation.

Some researchers found significantly lower level of serum copper and zinc in pre-eclampsia among Indian, Arabian, and Nigerian populations $s^{2,3,7}$, while others did not find any association between serum copper and zinc with the occurrence of pre-eclampsia in Sudanese and Iranian populations ${ }^{13,16}$. Though association of decreased serum copper and zinc with preeclampsia was not established yet we cannot negate it, as we found increased trend of serum copper and decreased trend of serum zinc in pregnancy (both pre-eclampsia and without preeclampsia) compared with non-pregnant women, and both were reduced in pre-eclampsia compared to normal pregnancy.

If we detect reduced level of serum copper and zinc in pre-eclampsia, we can take necessary action by supplementing copper and zinc throughout the pregnancy and prevent further complications of pre-eclampsia. Our sample size was small due to limitation of time and fund. We did not assess baseline copper and zinc status prior to study which could give us more significant change of trace elements in pregnancy.

In conclusion, there seems to be no significant association of serum copper and zinc level with pre-eclampsia yet reducing trend of both copper and zinc in pre-eclampsia needs further study categorizing severity of pre-eclampsia and including eclampsia with larger sample size after assessing baseline copper and zinc status prior to study. This may give more information about the changes of trace elements in pregnancy.

\section{References}

1. Dutta DC. Textbook of Obstetrics, 7 th Edn, Jaypee Brothers Medical Publisers, New Delhi 2014; 21930 .

2. Kanagal DV, Rajesh A, Rao K, Devi UH, Shetty H, Kumari S, Shetty PK. Levels of Serum Calcium And Magnesium In Pre-Eclamptic And Normal Pregnancy: A Study From Costal India. J Clin Diag Res 2014; 8(7): 01-04.

3. Al-Jameil N, Tabassum H, Al-Mayouf H, Aljohar HI, Alenzi ND, Hijazy SM, Khan FA. Analysis of Serum Trace Elements-Copper, Manganese and Zinc In Pre-eclamptic Pregnant Women By Inductively Coupled Plasma Optical Emission Spectrophotometry: A Prospective Case Controlled Study In Riyadh, Saudi Arabia. Int J Clin Exp Pathol 2014; 7(5): 1900-10.

4. Sarwar MS, Ahmed S, Ullah MS, Kabir H, Rahman GKMM, Hasnat A, Islam MS. Comparative Study of Serum Zinc, Copper, Manganese and Iron In Pre-eclamptic Pregnant Women. Biol Trace Elem Res 2013; 154: 14-20.

5. El-Moselhy EA, Amin HH, El-Aal HMA. Maternal Serum Calcium and Trace Elements Copper and Zinc Among Pre-eclamptic Women In Cairo, Egypt. Egyptian J Hosp Med 2010; 41: 520-31.

6. Vasiljevic N, Vasiljevic M, Plecas D. The Role of Nutritional Factor In Pre-eclampsia And Eclampsia. Shyte Arch Celok Lek 1996; 124(56): $156-59$.

7. Akinloye O, Oyewale OJ, Oguntibeju OO. Evaluation of Trace Elements In Pregnant Women With Pre-eclampsia. Afr J Biotech 2010; 9(32): 5196-202.

8. Ferrier DR. 'Lippincott's Illustrated Reviews: Biochemistry, $6^{\text {th }}$ Edn. Lippincott William and Wilkins Philadelphia, New York 2014; 48.

9. Satyanarayana U, Chakrapani U. Biochemistry, $4^{\text {th }}$ Edn. Elsevier, New Delhi 2014; 416-20.

10. Rajeswari M, Naimisha M, Suneel B. Copper, Zinc, Vitamin C And Oxidative Stress Can Causes Iron Deficiency Anaemia in Pregnant Women. Int J Appl Biol Pharma Tech 2013; 4(1): 267-71. 
11. Ashraf M, Salam A, Nasarullah M, Khurshid R, Ahmed Z. Maternal Serum Zinc Concentration In Gravida Suffering From Pre-eclampsia. APMC 2007; 1(1): 24-27.

12. Akhtar S, Begum S, Ferdousi S. Calcium and Zinc Defficiency In Pre-eclamptic Women. J Bangladesh Soc Physiol 2011; 6(2): 94-99.

13. Abdellah A, Abdrabo AA. Assessment of Serum Calcium, Magnesium, Copper and Zinc Levels In Sudanese Pregnant Women With Pre-eclampsia. Glob Adv Res J .Med and Med Sci 2014; 3(2): 033-36.

14. Rafeeinia A, Tabandeh A, Khajeniazi S, Marjani AJ. Serum Copper, Zinc and Lipid Peroxidation In Pregnant Women With Pre-eclampsia in Gorgan. Open Biochem J 2014; 8: 83-88.

15. Lambe S, Mahajan B, Muddeshwar $\mathbf{M}$. Comparative Study of Serum Calcium, Magnesium And Zinc Levels In Preeclampsia And Normal Pregnancy. Int J Recent Trends Sci Tech 2014; 9(3): 422-26.
16. Golmohammad LS, Amirabi A, Yazdian M, Pashapour N. Evaluation of Serum Calcium, Magnesium, Copper And Zinc Levels In Women With Pre-eclampsia. Iran J Med Sci 2008; 33(4): 231-34.

17. Kushtagi P, Rao K, Jacob A. Serum Minerals Calcium, Magnesium, Copper and Zinc In Pregnancy Induced Hypertension. J Obst Gynae India 1993; 13(1): 33-36.

18. Ugwuja EI, Ejikeme BN, Ugwu NC, Obeka NC, Akubugwo EI, Obidoa O. Comparison of Plasma Copper, Iron And Zinc Levels In Hypertensive And Non Hypertensive Pregnant Women In Abakaliki, South Estern Nigeria. Pak J Nutr 2010; 9(12): 1136-40.

19. Meram I, Bozkurt AI, Ozcipici B, Ahi S, Ozgur S. Plasma Copper And Zinc Levels In Pregnant Women In Gaziantep, Turkey. Saudi Med J 2003; 24(10): 1121-25. 